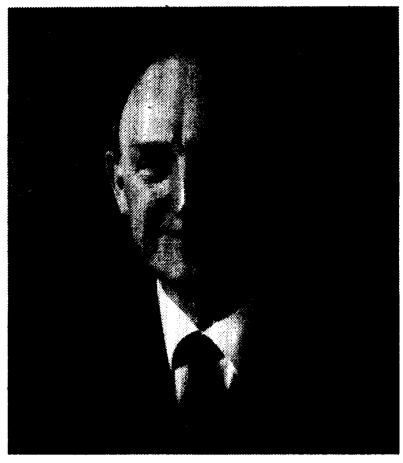

\section{Coupling Technology to National Needs}

SPIE-The International Society for Optical Engineering has always had technology transfer as one of its missions. The success of this activity is apparent in all of SPIE's activities, and particularly at the meetings and in the publication program. Many attendees at the various technical meetings of the society are not members of SPIE but are there for the interaction with members of the research and development community in optical science and engineering and with those who are talking about and demonstrating new technologies. In the same way, the readership of all the society's publicationsthe journal Optical Engineering, the proceedings, or books from the Optical Engineering Press-is much broader than just the membership.

In Albuquerque, from August 22 to 27, a new activity will take place to enhance the society's technology transfer mission: the SPIE Southwest Conference on Coupling Technology to National Needs (hence, the title of this editorial). The purpose of this meeting is, to quote from the briefing paper about this conference, to bring together:

- the research and development community that is developing and seeking to apply technology;

- industry executives in corporate planning, product development, and market development responsible for innovation; and

- federal and state policy makers who have decisions to make on government policies and programs that foster technological innovation; and place them in a structural environment that will allow them to:

- relate a range of technology development to specific market needs and identify federal and state programs that can assist in the application of those technologies; and

- discuss and debate key national and regional public policy issues related to the application and commercialization of advanced technology in the designated technology fields and national needs.
The fields of technology that will be focused on and that are listed in the briefing paper include:

$$
\begin{aligned}
& \text { - Optical Materials } \\
& \text { - Laser Technology } \\
& \text { - Range } \\
& \text { Instrumentation } \\
& \text { - Imaging Technologies } \\
& \text { - Photochemical } \\
& \text { Technology } \\
& \text { - Space-Related Technologies } \\
& \text { - High-Performance Computing } \\
& \text { and Data Fusion } \\
& \text { - Nanotechnology and Metrology } \\
& \text { - Sensor Technology } \\
& \text { - Photonics and Semiconductor } \\
& \text { Technologies }
\end{aligned}
$$

The areas of national need that these fields can be applied to are listed and include: transportation, energy, imaging, information processing and telecommunications, the environment, public safety, biomedicine, and manufacturing.

The format for the conference will include concurrent market and technology sessions "to explore the relevance and applicability of a range of technologies to those market areas." Plenary sessions will "highlight existing federal and state programs aimed at assisting technology application and commercialization and focus on national, regional, and state public policy issues related to technology application and commercialization."

Of particular interest to me was that the organizers have made a special point that "federal and state government agencies will be able to present their assistance policies and programs to both industry and the research and development community."

I for one certainly hope that this conference is a success since it is much needed and could provide a model for other such regional meetings. I would like to thank Joseph Houston and Ray Mataloni for making the briefing paper available to me so that I could prepare this brief editorial. Further information can be obtained from SPIE headquarters in Bellingham. 
June 1993

From Numerical to Symbolic Image Processing: Systems \& Applications G. Vernazzs

Dipartimento di Ingegneria Biofisica ed Elettronica

Universita degli Studi di Genova

Via Opera Pia, 11a

16145 Genova, Italy

+39 10 353-2755 • +39 10 353-2777 FAX

July 1993

Visual Communication and Image

Processing IV

Cheng-Tie Chen

Belloore

445 South St.

Morristown, NJ 07962

201/829-5151 • 201/829-5884 FAX

Hsueh-Ming Hang

Center for Telecommunication Research

National Chiao-Tung University

Hsinchu, Taiwan

$+886 / 35-712121 \times 3298 \bullet+886 / 35-723283$

FAX

Kou-Hu Tzou

COMSAT Labs.

22300 Comsat Drive

Clarksburg, MD 20871

301/428-4663 - 301/428-7747 FAX

September 1993

Optical Science and Engineering in Canada

C.P. Grover

National Research Council

Institute for National Measurement Standards

Outawa, Canada K1A OR6

613/993-2098 • 613/952-1394 FAX

Optical Engineering in Hungary

Tivadar Lippenyi

HUNGOPTIKA

Tartsay u.24

Budapest H-1120, Hungary

3611563985 • 3611563985 FAX

Zoltan Fuzessy

Technical Univ. Budapest

Department of Physics

Balazs Bela u.36.IV.8.

Budapest $\mathrm{H}-1094$, Hungary

$3611666361 \cdot 3611666808$ FAX

October 1993

Microlithography

James R. Sheats

Hewlett-Packard Company

3500 Deer Creek Road

Palo Alto, CA 94304-1392

415/857-5987 • 415/857-2379 FAX

November 1993

Acquisition, Tracking, and Pointing

Mohammed A. Karim

University of Dayton

Center for Electro-Optics

300 College Park

Dayton, Ohio 45469-0227

$513 / 229-2241 \cdot 513 / 229-3433$
December 1993

Magnetospheric Imagery and Atmospheric Remote Sensing

Supriya Chakrabarti

Boston University

Center for Space Physics

725 Commonwealth Avenue

Boston, MA 02215

E-mail: supo@bu-ast.bu.edu

617/353-5990 • 617/353-6463 FAX

Manuscripts due May 1, 1993.

January 1994

Infrared Technology

Marija S. Scholl

Alenlea Associates

P.O. Box 27408

Tempe, AZ 85285-7408

E-mail: msscholl@al.com

602/491-7814

Manuscripts due May 1, 1993.

February 1994

Optical Interconnects and Packaging

Sing Lee

University of Califormia/San Diego

E\&CE Department

La Jolla CA 92093-0407

619/534-2413 • 619/534-1225 FAX

Manuscripts due July 1, 1993.

March 1994

High Heat Flux Optical Engineering

Ali M. Khounsary

Argonne National Laboratory

Advanced Photon Source, APS 362

Argonne, Il 60439

708/252-3384 - 708/252-3222 FAX

Manuscripts due Aug. 1, 1993.

April 1994

Optical Pattern Recognition

Joseph L. Homer

Rome Laboratory

EROP

Hanscom AFB, MA 01731-5000

$617 / 377-3841 \cdot 617 / 377-5041$ FAX

Bahram Javidi

University of Connecticut

School of Engineering

Department of Electrical and Systems

Engineering

Room 312, U-157

260 Glenbrook Road

Storrs, CT 06269-3157

203/486-4816 • 203/486-3789 FAX

Manuscripts due Sep. 1, 1993.

\section{May 1994}

Semiconductor Infrared Detectors

Antoni Rogalski

Institute of Technical Physics

Military Academy of Technology

Kaliskiego 2

00-489 Warsaw, Poland

$4822362109 \cdot 4822362254$ or

4822120757 FAX

Manuscripts due Oct. 1, 1993.
June 1994

Optical Science \& Engineering in India

Rajpal S. Sirohi

Indian Institute of Technology

Applied Optics Laboratory

Physics Department

Madras-600 036, India

044-2351365 ext. 221 0 044-2350509 FAX

Manuscripts due Nov. 1, 1993.

July 1994

Adaptive Wavelet Transforms

Harold H. Szu

U.S. Navy

Naval Surface Warfare Center

Code R44

10901 New Hampshire Avenue

Silver Springs, MD 20903-5000

301/394-3097 • 301/394-3923 FAX

Manuscripts due Dec. 1, 1993.

August 1994

Digital Image Recovery and Synthesis

Paul S. Idell

Air Force Phillips Lab.

PL/GPOA

390 B Great Road, \#18

Acton, MA 01720

612/377-3663 • 617/377-3661 FAX

Manuscripts due Dec. 1, 1993.

September 1994

Optics in South Africa

Hannes Markusse

ELOPTRO

Institute of Atomic Physics

P.O. Box 869

Kempton Park 1620, South Africa

Maurice W. McDowell

CSIR/Production Technology Div.

Productiontek

P.O. Box 395

Pretoria 0001, South Africa

27128413418 • 27128412131 FAX

Manuscripts due Jan. 1, 1994.

October 1994

Optics in Russia

V. Ya. Panchenko

Scientific Research Center for Technological Lasers

Russia Academy of Sciences

B-333, Gubkina, 3

117971 Moscow, Russia

E-mail: ilo@compnet.npimsu.msk.su (095)135-54-30 - (095)334-02-01 FAX Manuscripts due March 1, 1994.

November 1994

Micro-Optics

Chandrasekhar Roychoudhuri

University of Connecticut at Storrs

Photonics Research Center

MS-157, Room 312

260 Glenbrook Road

Storrs, CT 06269-3157

203/486-4816 • 203/486-3789 FAX

Manuscripts due April 1, 1994. 